\title{
Development and Challenges of English Taught Programs in Asian Countries: Take Taiwan as an Example
}

\author{
Jia-chen Chuo ${ }^{1}$ \\ Department of Applied Foreign Languages \\ Shih Chien University, Taiwan \\ Yen-Hui Lu \\ Department of Applied Linguistics and Language Studies \\ Chung Yuan Christian University, Taiwan
}

\begin{abstract}
Under various reasons, English Taught Programs (ETPS) are burgeoning in universities. We see such programs not only in European countries but also in Asian ones. At the same time, the research of English as Medium of Instruction (EMI) also gets much momentum in academia. However, the challenges faced by such programs in different areas will vary. This research will first brief the ETPs in Asian countries. An overview of the background of such program will be studied. Challenges faced by the managers (administrators), instructors and students in these programs will also be discussed. While Asia is composed of countries with diverse historical backgrounds, the case in Taiwan will be the focus of discussion. Unlike Singapore, Malaysia, or Indonesia, which shared a common colonial history, countries such as Korea, Japan and Taiwan are more similar in that English is not one of their official languages. As ETPs seem to be the trend in the future, suggestions are also provided for future improvement.
\end{abstract}

Keywords: English as Medium of Instruction (EMI), Curriculum, Asian countries English Taught Program

I. Introduction: the rising of English Taught Programs (ETPs)

As the world is moving fast to become a globalized village, English language seems to be the medium to foster communication, not only in business world but also in universities. In a 2014 survey on the ETPs in European higher education, there are 8089 ETPs in the European countries of the study, a dramatic increase from 725 programs in 2001 (Wächter \& Maiworm, 2014).

In terms of EMI research, we find that the U.S. has focused on similar problems caused by her dependence on International Teaching Assistants (ITAs) long ago. Early EMI workshops and courses were designed for doctoral candidates and post-docs who are from outside the U.S. and will share some teaching loads of their advisors and teach native students as well as some international students.

Unfortunately, there are yet little empirical research focusing on EMI instructors partly because EMI instructors are mostly not familiar with research methods in educational field. While they are already heavy-loaded by their double time spent in preparation for EMI courses and the research demand in their own fields, such as economics, finance, it is only natural that EMI instructors have no more time to spare to the research on the effectiveness of using English as an instructional language and the frustration an EMI teacher may have.

Despite the controversy behind EMI, such instruction models are used in more universities than ever. Although from surveys and statistics, we can see that EMI and ETPs are a global phenomenon, the context for this phenomenon varies from country to country. This study aims at casting a closer look at the ETPs in Taiwan and the challenges and problems faced by the program managers, teachers and students in the country.

II. ETP development in Asia and in Taiwan

Asian countries develop various cooperation patterns for their international education. Malaysia, for examples, sees itself as a regional educational hub and cultivates partnership with Anglo universities and thus provide EMI programs.

\footnotetext{
${ }^{1}$ Corresponding Author.

148
} 
In Japan, the government initiated the "Global 30 Project for Establishing Core Universities for Globalization," with the aim to attract 300,000 overseas students into Japan by the year 2020. ETPs in Japan are also regarded as alternative sources to compensate the declining rate of university enrolment. Waseda University, one of the 13 participating universities, provides 20 BA and MA degrees through English (2018). In Hong Kong, six out of the eight government-funded universities are English medium universities. Out of parental demand, more secondary education now provide EMI courses to prepare students for future EMI environment. In Korea, universities also encourage instructors to offer EMI courses since the 1990s. The policy successfully increases the number of Korea's international students to 78,000 in 2012 (Hou et al., 2013, cited in Tsou \& Kao, 2017). In the same vein, Taiwan government launched two major national projects to urge the open-up of local campuses to international students, expecting to attract 120,000 foreign students by 2020.

In 2003, there were about 4,697 courses taught in English in Taiwan (Lo, 2010). The number increased dramatically to 24,077 in 2014 (Tsou \& Kao, 2017). In terms of ETPs, there were 19 ETPs in 2006, offering Bachelor degrees while in 2017, the number increases to 39 (CADC, 2018). In the beginning, ETPs were mostly provided in MA and PhD level, while in recent years, there's a steady increase of ETPs in BA level. In 2014, Taiwan government officially encouraged the establishment of ETPs and EMI courses with financial support. Thirty-six ETPs from 16 universities were financially aided (Ke, 2015).

Around the world, ETPs were established for various reasons. The earliest attempt to establish ETPs in European countries is to "increase the international mobility of students" (Ibid., p. 25). In addition to the reasons mentioned above, some other shared goals are to facilitate understanding among various countries and to provide equal opportunities for young researchers in low and middle income countries ${ }^{2}$. For policy makers, building the country's English language capacity and prepare their students for fierce competition in a world market are also important considerations for ETPs (Dearden, 2014). Universities may also provide ETPs in order to receive international recognition of local education (for example, in Kazakhstan) ${ }^{3}$. These seem to be the shared factors while some other factors will vary according to various social and cultural context.

Although tuition income increase is also mentioned as one of the objectives, it is not the most important one. In fact, through many scholarship schemes, European institutions try to "remove or reduce barriers possibly preventing students from becoming internationally mobile" (Ibid., p. 25). Through setting up ETPs, universities can also produce more research papers in English, which will help move up their rankings in international education market. It is interesting to note that teachers in ETPs focus more on complete different reasons and goals. EMI teachers usually see themselves as someone "to improve communication, to exchange ideas and create relations between countries, even a way of facilitating world peace" (Ibid., p. 16).

The increase of ETPs probably has much to do with the development of new type of market-oriented universities. While educational institutes search for more student fees to survive, it is not difficult to find that international education could be lucrative and attract tuition-paying students. Although Knight (2008) lists political, economic, academic and cultural as the four reasons for universities developing international education, Kirkpatrick (2011) also comments that "for the providers, the benefits are overwhelmingly financial" (p. 6).

In Taiwan, there are ETPs aimed at attracting local students as well as international students. Programs focusing on different targets will reflect different problems. One of the major objective for ETPs in Taiwan is to compensate the loss of local students caused by the dropping enrollment rates in universities and the competitiveness of global educational market. Many local students opt tertiary educational opportunities abroad. In 2010, only 556 high school graduates studied abroad, while in 2015, the number increased to 1443 (Lin, 2017). As China and Germany make it easier for Taiwanese students to apply, it is estimated that more students will study abroad this year. In Taiwan, college enrollment decrease will affect private universities most. This will somewhat explain the reason why private institutes in Taiwan take ETPs as one of the alternatives for the sustainable development of the institute ${ }^{4}$.

\footnotetext{
${ }^{2}$ Students pay relatively less to receive an all-English education without flying to English-speaking countries and spending extra living costs.

${ }^{3}$ Or, "to be in line with established world standards of teaching and assessment" (Dearden, 2014, p. 15).

${ }^{4}$ In Taiwan, students will take government-run universities as their first priorities. If their test grades are not good enough to enter national universities, they will then enroll in private colleges.
} 
The debate on EMI and ETPs is sometimes heated in Taiwan, particularly when university administrators make it a rule that newly recruited professors should provide EMI courses. The ability to teach in English is also one of the priorities when administrators are interviewing new candidates. The debate will last for several days, questioning the connection between EMI and internalization, and then become quiet once the heat is gone. Granting English the status of second official language is also proposed several times in government policy discussion. The proposal never went into policy for doubts and suspicion on its possible impact on national solidarity. Similar debate can also be found in Korea, where some universities have implement an English-only policy and public controversy is mainly over the students' right to learn in their first language (Kym, 2014).

As changes of language policy will usually incur opposition, the debate on Taiwan's ETPs also focus on the opposition from instructors who are partially forced to change their instructional language. One experienced EMI professor Xin-tien Liao also reminded that the administrators should understand that is not easy, sometimes painful, for a teacher to switch his/her language of instruction. The policy maker should be more sympathetic to the emotional aspect of EMI teachers (2016).

\section{Challenges facing EMI programs}

A common definition of EMI is adopted: "the use of the English language to teach academic subjects in countries or jurisdictions where the first language (L1) of the majority of the population is not English" (Dearden, 2014, p. 4). What we find lacking in this definition is the more details about the faculty and students. Who should be qualified to teach EMI courses? Will the hiring of native English instructors solve all the problems? What are purposes of students enrolling in ETPs? For local students, the main goal might be to improve their English proficiency, while for international students, the main goal might be to experience local culture in the language of English. The administration's aim to receive more fees has in fact cause difficulties in the classroom.

If students are looking for subjects taught in English, why don't they just go to the UK, the US or any other English speaking countries? It seems that ETPs are more affordable means for students who crave education in English. UK and US education system and curricula naturally will be copied (a knock-off?) in every corner of the world or are local colors accepted? Although it is still debatable whether ETPs are localized UK and US education, the increase of ETPs in the international educational market is made possible with the view that proficiency in English is a key indicator of future economic prosperity, no matter for students, parents or universities.

EMI programs are controversial and divisive in nature. They are controversial because of the debate on nationality (being unpatriotic), educational efficiency (learning contents in L2) and language acquisition (better learning results via L1). They are divisive because of their relative high tuition fee in local market and thus might exclude the lower social-economic groups from having access to the educational opportunity ${ }^{5}$. Kirkpatrick doubts that the internationalization attempt of recent corporate- and market-oriented universities may result in Englishization and thus further strengthens the UK-US "primacy in the realm of higher education" to promote Anglo-Saxon values and to jeopardize home cultures (UK/US Study Group, 2009: 21, cited in Kirkpatrick, 2011, p. 11; Dearden, 2014; Toh, 2016). It is such concern of Englishlization that EMI is rejected because of political reasons, such as to protect national identity and the freedom to use a home language in learning. In the past, for example, in Israel, EMI or CLIL courses in English will attract hostile media coverage. In Indonesia, EMI programs were ordered by the court to stop because of the fear that Bahasa Indonesia may be associated with the poor while English will be associated with the elite class (Dearden, 2014).

Unlike other disciplines, ETP programs are usually in a state of flux. They are the result of government promotion, dropping birth rates and economic changes. In Dearden's survey, nearly $62 \%$ of respondents reported EMI policy changes in their countries (2014). When governments stop subsidizing such programs, the future of ETPs become uncertain. It is exactly such uncertainty that brings in the problems in ETPs. The problems can be categorized into three dimensions: administration, instructors and students.

\footnotetext{
${ }^{5}$ The best government-run university, National Taiwan University, is about to set up an ETP, recruiting 120 international students and 40 local students, with the tuition fee of USD 20,000 per year, approximately 6 times that of the non-Englishtaught programs.

150
} 


\section{For Administrators and Mangers}

In ETPs, one would presume that students' English proficiency is a default. However, we saw instructors' complaints about students' lack of confidence in English even though they pass the language requirement to enter the program. For example, in an ETP in University of Màlaga in Spain, owing to university regulations, Common European Framework for Reference (CEF) B1 English level can only be recommended, not required, for students enroll in such program (Barrios et al., 2016). In Japan, Toh (2016) also notices that universities admit students with less than satisfactory English proficiency levels because of their desperate need to have international students.

Managers of ETPs will also frequently worry about the level of the EMI teachers' English proficiency as local teachers may sometimes over-estimate their abilities in teaching contents in English. A common myth is that as long as one can speak English, he/she can teach in English. It might be shocking to know that 20\% of the local school teachers in Turkey only have a CEFR (Common European Framework of Reference) A2 language level (Dearden, 2014). In Taiwan, when a local teacher is recruited for teaching EMI courses, it is not required of the teacher to provide language proficiency certificate. Usually the recruiting committee will test candidates' English proficiency through interviews. However, some senior local teachers, who were assigned to teach EMI courses in earlier years, cannot speak English fluently and some of them, because of the lack of content EMI teachers, still teach nowadays. This is also one of the causes that student performance is poor in their professional areas. Not only instructors will teach much better in their native language, students also learn better with their mother tongue (UNESCO, 2008; Dearden, 2014).

Such loose check on students' and instructors' English proficiency level has become the source of frustration from students and instructors, such as mixed-level group (for instructors) and communication weakness in class activities (for students). On top of that, administrative staff's incompetence in English also cause inconvenience for international students and instructors. If university regulations and announcements are not ready in English, students and instructors will find their rights compromised. International students came to believe that they are coming to a place where English is the key to an Asian country only to find that outside the classroom, they can barely survive, from registration to daily life, with the vary scant ability of local language.

One of the common challenges, especially in non-English speaking countries, is the low motivation of local teachers to conduct courses in English. Most research mentions the causes for such phenomena to be heavy teaching load and less incentive to promotion. However, the lack of emotional support of local EMI instructors is also something the administration needs to address.

What, then, is the purpose of ETPs in a university? The university needs to have clear goals for administrators, instructors, and students to follow. Toh even criticizes that EMI is a facile and superficial means for educational institution to advertise the difference from traditional L1 education. If administrators do not strengthen their competence in running ETPs, they are definitely going to have a "sure but gradual demise" (Toh, 2016, p. 2). The resistance from inside institute to innovation and change should also be dealt with delicacy in order not to create traumatizing experiences for all personnel involved (Ibid.).

\section{For instructors}

In Dearden's preliminary study, she found that most teachers actually have very limited experience and understanding of teaching through EMI. My own experience is that the administrators didn't even tell me the background of the students and the educational goals of such ETP programs when I was first told to teach ETP students. Thinking that I would just need to teach in English and present all my materials in English in the first class, I was frustrated to find a full room of bored students with confused eyes because of the jokes I told in class, which were in my local classes resting time for a long lesson. The first semester was a disaster for both instructor and students, hoping not to see each other next semester. That is exactly what many EMI teachers will do. Once they have the chance to say no, they will get themselves out of the Herculean task. While universities reap the financial benefits from fee-paying students, it is EMI teachers that struggle with the quality of their international classroom. The first question to ask is "can local knowledge be completely conveyed through a language that is not their native tongue?" Kirkpatrick (2011) finds that the essence of the local knowledge will be altered through translation, citing traditional Chinese medicine as an example. He warns that "translation may radically alter the knowledge translated" (Ibid. p. 12) by citing the unsatisfactory translations of the fundamental concept of $q i$ in Chinese medicine. 
This somewhat conform to Dearden's survey on teacher's ideas of the attributes of an EMI teacher. One of the most important attributes is "the ability to explain difficult concepts" $(2014$, p. 24$)$. It is also interesting to note that in the same survey, 9 respondent countries think that mathematics can [easily] be taught through EMI while only one country thinks that religious education should be taught in English (through translation) (Ibid.).

For these who are not involved in EMI teaching, such as administrators, they may think that EMI is simply a matter of "translating course material and slides from L1 to L2" (Ibid., p. 23). However, EMI teachers need to do more adjustment in their teaching than just that:

They would need to know how to modify their input, assure comprehension via student-initiated interactional modifications and create an atmosphere where students operating in an L2 are not afraid to speak; all this whilst taking into account the many cultural differences present in the room and the potentially different language levels of individuals.

(Dearden, 2014, p. 23)

EMI teachers working in a multilingual and multicultural learning environment may also face communicative, intercultural and didactic challenges. They are constantly mobilizing in the EMI triangle: the interplay between language, pluridiversity and local linguacultural context ${ }^{6}$. Teachers, even with second language proficiency, will find that they face challenges because of cultural differences. Jae Woong Youn, assistant professor from Woosong University, South Korea, shared his experience in a multi-cultural classroom. One man stood up and shouted at another girl and asked her to shut up her mouth. The instructor later found that the man and woman shared the same muslin background. While in muslin culture, women are not supposed to talk loudly in public. The male students thought he was doing the instructor a favor to ask the girl to behave. From the experience, it is clear that EMI teachers should not only be equipped with language proficiency, but also have the awareness of the diverse cultural backgrounds of the students. That is to say, EMI teachers, more than non-EMI ones, need to be culturally intelligent. Research finds that if teachers do not have multi-cultural background, they are prone to repeat their own cultural experience in his/her international classroom (cited in Wang, 2007).

EMI pedagogy is particular challenging to traditional Asian teachers, as well as students, who are used to monologic approach, rather than the dialogue or interaction approach. ETP managers usually assign existing faculties to EMI courses without considering the extra load for preparing a lesson in EMI. This also naturally leads to the result that $83.6 \%$ of the respondents in Dearden's survey felt that there were not enough qualified teachers and $60 \%$ reported that there were no guidelines about how to teach through EMI (2014). The question one will ask is then, "what are the attributes of a qualified EMI teacher?"

In Vinke, Snippe \& Jochems's survey in 1998 on Dutch EMI teachers, 70\% agreed that they spent more time in preparing EMI courses; $60 \%$ admitted that sometimes it is not easy to express the ideas well in English. In the same research, they found that in an EMI class, $40 \%$ of the time were spent in lecturing; $20 \%$ of the time were spent in repeating the materials for students and $10 \%$ of the class time were spent in interacting with students and silence (cited in Lo, 2010). Lo thus concluded that in EMI classrooms, there are more lectures than interactions (Ibid.). It seems that an EMI class, like its non-EMI counterpart, is still teacher-centered. There is not clear indication about the percentage between lecture and interaction. For some professional contents, it seems very difficult to involve students in the discussion, since to understand the contents in English itself is already difficult for students to handle.

The stark gap of language proficiency between local students and international ones will also causes difficulties for teacher's instruction. One professor even expresses his frustration by saying that what international students will learn in 6 minutes, local students won't even understand in six hours. The gap behind this is not so much because of the intellectual ability of the students but the experiences of the students. International students usually have prior knowledge on their profession and more mature than their local peers.

From Lo's research, we also find that non-native English speaking (NNES) teachers do not have much confidence in teaching a subject with a language that is not their native tongue. However, NNES teachers actually have more advantage than their native English speaking counterparts. NNES teachers are truly bilingual with multi-cultural experiences. They are more sympathetic about students' learning problems. Students tend to take NNES teachers as their role models in terms of their foreign language ability. Ponterotto et. al. also indicate that bilingual teachers can better create a multi-cultural environment (Lo, 1995).

\footnotetext{
${ }^{6}$ Course descriptions of the EMI workshops provided by University of Freiburg in Germany 152
} 
It is hard for EMI teachers to remain neutral and not biased in an international classroom. In the U.S., teachers tend to assign individual tasks to Anglo-Saxon students while with African-American students, they tend to give group tasks. Sometimes teachers will interact more often with middle- and upper-class students in their classrooms. These same groups of students are of a higher percentage to be liked by their school teachers. Research also finds that teachers usually expect middle- and upper-class students to be good students, with less morality issues (Wang, 2007). Similar bias and prejudice might also exist in teachers facing a conglomeration of students from different countries. From the promotion of EMI teacher training programs, we find that most courses are designed to strengthen teachers' presentation and interaction skills in the classroom. However, we do not see many courses addressing such prejudice issues, as if they are a default of EMI teachers. Unfortunately, it is not. Teachers are not neutral and they need to learn how to deal with related issues.

What, then, should be the role of EMI teachers? EMI teachers don't seem to see themselves as language teachers. However, if they are faced with a classroom of students whose language abilities are only for communication, not yet for academic purposes, what should they do? Research finds that EMI teachers believe that sutdents are responsible for their own improvement in English (Dearden, 2014). Improvement will not be accomplished overnight. We notice many EMI teachers spending extra hours instructing the contents in their local language, without extra pay.

Although governments or universities provide incentives to EMI lecturers, such as providing TAs and increase hourly pay by $50 \%$, we have found that such incentive is not very attractive since TAs do not help much with the preparation work of the EMI lecturer. In order to get 50\% extra stipends, EMI lectures have to fill out a lot of forms to prove that their EMI courses pass average course evaluation and thus are worthy of the rewards. However, while EMI instructors are trying new teaching styles without much experience and the class constitutions are different every semester, not all EMI teachers will receive the stipends.

\section{For students}

Many EMI students, particularly Asians, enter EMI programs with the major aim to improve their English proficiency. They are not prepared for what adjustment they are about to make intellectually. Asian students are used to having passive learning in the classroom, they assume that they can just sit there to enjoy the onedirection lectures without making any efforts in classroom. Some students are reluctant to adapt themselves to the new interactive way of learning and opined that they prefer traditional way of learning. This causes problems not only for students but also for teachers because any interactive activities would fail if students do not participate in the activities.

Most EMI research focuses on student reception of EMI instruction. Many worry that students' knowledge will be compromised because of the language incompetence of local instructors and students (Han \& Singh, 2014). In surveys on student satisfaction of EMI courses, most students think positively about ETPs and believe that their English proficiency will be improved (Lo, 2010). The research results, however, on the increase of students' English proficiency and professional knowledge build-up are not consistent. Some believes that ETPs will help improve student's English proficiency, while others claim the opposite. With limited resources to provide teachers with necessary support and the lack of experiences about such practice, we have to admit that there are too many variants on the outcome research of students in ETPs.

What do students in ETPs expect? For local students, it is the English proficiency and the learning experience with international students. How about for foreign students who come to a country with little local language ability? Do they expect to know about a country through a foreign language? Glenn Toh even presents the extreme case in Japan:

In a society where conformity is valued traditionally, Global 30 students may well stand out as "oddballs" or "addendums" in the larger backdrop of local students populating university campuses. The question that can be asked is that of how genuinely welcome these foreign students would be on Japanese soil...they are studying in a language which the politically powerful continue to regard as a threat. $(2016$, p. 8)

IV. Suggestions

A solid EMI program will not prosper without a clear language policy in the administrative level. Program managers and instructors will then be able to propose constructive goals and projects based on the policies. Current survey has shown that such policies are non-existent in Asian countries developing ETP programs or such policies were not made public and clear (Dearden, 2014). 
This is probably why in some ETPs, there are some inappropriate arrangement of courses. In Taiwan, some courses were taught in English simply because they find instructors with corresponding language ability. Sometimes, liberal arts course, such as Chinese ${ }^{7}$ in Taiwan's ETPs, will also be taught in English. One cannot but wonder why. There is not much planning behind this random arrangement of EMI courses. The administrators need to have a learning blueprint behind the planning of an EMI curriculum.

Dearden's survey found that "there is little or no EMI content in initial teacher education (teacher preparation) programs and continuing professional development (in-service) courses" (p. 2). Studies have shown that students, instructors, as well as administrators should be prepared for the EMI program they are about to enter (Ibid.; Toh, 2016). Courses and workshops should be organized for students and teachers. Both EMI instructors and students need to know their role expectations and their impact.

In addition to professional knowledge, EMI teachers in a multicultural classroom should also be equipped with cultural literacy. We may adopt the checklist that is designed for counselors or social workers dealing with students from various backgrounds. Multicultural literacy means that a teach knows cultural knowledge and understands various cultures. They need to know the definition of "culture," "ethnic," "mainstream," "prejudice," "ethnocentric," "cross-culture," and so on (Wang 2007, p. 162). Cross-cultural literacy also means the ability to deal with cultural differences among students. Teachers need to have the ability to analyze and criticize cultures. Self-reflection on cultures is also crucial. Last but not least, teachers should have the ability to always learn from various cultures (Ibid.).

From the workshops and courses held for EMI instructors and students, we will find that most emphasis was placed on enhancing language and communicative skills for teachers to conduct a class in English. This seems to imply that one of the main educational goals in EMI classrooms is to communicate. Communication involves interaction. As a result, an EMI classroom is not a lecture-only classroom. A project-based learning approach may be a good choice for such international classroom. In terms of practical classroom management, easier vocabulary and sentence structure will be preferred to convey professional knowledge. It is found that in EMI classrooms, teacher should design activities, discussions and peer evaluation $(\mathrm{Ke}, 2015)$.

\section{Conclusion}

It is interesting to note that EMI and ETPs are still not a stable idea; it is thus developed under the needs of finance and the fast changing future. Glenn Toh's subtitle of his book on EMI in Japanese higher education perfectly reflects the problems in ETPs - presumption, mirage or bluff. Toh even argued that the implementation of EMI to institutes in Japan, where Japanese had all long been the only medium of instruction, will be "an extremely difficult, if not unsustainable, undertaking" (2016, p. 2).

As many educational institutes feel positive about English Taught Programs, educational managers and administrators, however, usually underestimate the complexities and challenges faced by the agents in such programs. What they should realize is that "the English-taught degree programme requires a language plan of its own, which will be complementary to the larger university policy and plan...to ensure a smooth and collaborative transition into English medium" (Marsh et al., 2013, p. 15). The importance of a language policy, after considering cultural background of one's country, cannot be overemphasized.

Before administrators think of financial benefits of ETPs, it is imperative of them to come up with multilingual language policies, so such ETP development is not going to be merely a celebration of Anglo-Saxon paradigm and control over international education. While developing ETPs to promote globalization, we should also consider the side effect that omnipresent English speaking will bring. Maybe Patricia Ryan, an English teacher in Dubai for 30 years, is right in calling our attention to language loss with her paradoxical Ted talk title: Don't insist on English.

\section{Bibliography}

Barrios, Elvira, López-Gutiérrez \& Lechuga, Glotilde (2016). Facing challenges in English Medium Instruction through engaging in an innovation project. Procedia: Social and Behavioral Sciences, 228, 209-214.

College Admission Committee (CADC) (2018, March 20) Retrieved from https://www.caac .ccu.edu .tw/apply107/query.php

\footnotetext{
${ }^{7}$ Chinese is a required course for at least two semesters in most Taiwan's universities. 154
} 
Corrigan, Paul C. (2015). English For the Medium of Instruction (EFMI) at a University in Hong Kong. The IAFOR Journal of Education, Vol. 3 (2). 158-169.

Dearden, Julie (2014). English as a medium of instruction - a growing global phenomenon. British Council.

Doiz, A., Lasagabaster, D., \& Sierra, J.M. (2013). Introduction. In A. Doiz, D. Lasagabaster, \& J.M. Sierra (Eds.), English-medium instruction at universities: Global challenges (pp. xvii-xxii). Bristol: Multilingual matters.

Han, Jinghe, Michael Singh (2014). "Internationalizing Education Through English Medium Instruction: Key Theoretic-Pedagogical Ideas," Research Project Report. Retrieved from

https://www.westernsydney.edu.au/_data/assets/pdf_file/0005/907691/3._HAN_and_SINGHWeb_version_.pdf

Ke, Chun Chu (2015, Feb. 11). Current status, challenges, and future prospects of EMI. Retrieved from http://www.geat.org.tw/englishcareer/50/\%E5\%85\%A8\%E8\%8B\%B1\%E8\%AA\%9E\%E6\%8E\%88\%E8\%AA\%B2\%Е7\%8F\%BE\%Е6\%B3\%81\%Е3\%80\%81\%Е6\%8C\%91\%Е6\%88\%B0\%Е8\%88\%87\%Е6\%9C\%AA\%Е $4 \% \mathrm{BE} \% 86$

Kirkpatrick, Andy (2011). Internationalization or Englishization: Medium of Instruction in Today's Universities. Hong Kong: Centre for Governance and Citizenship. The Hong Kong Institute of Education.

Knight, J. (2008). "Crossborder Higher Education," Paper presented at the $52^{\text {nd }}$ Annual Conference of the Comparative and International Education Society, New York, March 17-21.

Kym, Inyoung (2014). Students' Perceptions of EMI in Higher Education in Korea. The Journal of Asia TEFL, 11(2), pp. 35-66.

Liao, Hsin-tian (2016, March 23). Some words from an EMI instructor. Retrieved from https://tw.appledaily.com/new/realtime/20160323/822809/

Lin, Z. C. (2017, March 10). News. Retrieved from http://www.chinatimes.com/newspapers/20170310000425260114

Lo, Ya-Fen (2010). "Internationalization of Higher Education and the Challenges of English-Medium Teaching in Taiwan," Journal of Kao-Tech University, No. 39.

Marsh, D., Pavón-Vázquez, V., \& Frigols-Martín, M.J. (2013). The higher education languages landscape: Ensuring quality in English language degree programmes. Valencia, Spain: Valencian International University.

Ministry of Education [MOE] (2018, Feb. 19), Taiwan. Reference List of Universities/Colleges Providing Degree Programs Taught in English: 2018 Academic Year. Retrieved from https://www.taiwanembassy.org/uploads/sites/159/2017/12/List-of-English-Taught-2018-academicyear.pdf

Ponterotto, J. G., Alexander, C. M., Grieger I. (1995). A Multicultural Competency Checklist for Counseling Training Programs. Journal of Multicultural Counseling and Development, 23(1), 11-20.

Shinway Education (2013, Dec. 19). G30 project in Japan. Message posted to http://www.igo.cn/2010/news/lxxw/lxdt/2013/12/19/83580.shtml

Strotmann, B., Bamond, V., Lopez Lago, J. A., Bailen, M., Bonilla, S., \& Montesinos, F. (2014). Improving bilingual higher education: Training university professors in content and language integrated learning. Higher Learning Research Communications, 4, 91-97. http://dx.doi.org/10.18870/hlrc.v4i1.198

Toh, Glenn (2016). English as Medium of Instruction in Japanese Higher Education: Presumption, Mirage or Bluff? Switzerland: Springer International Publishing.

Tsou, Wenli \& Kao, Shin-Mei (2017). Overview of EMI Development. In Wenli Tsou \& Shin-Mei Kao (Eds.), English as a Medium of Instruction in Higher Education: Implementations and Classroom Practices in Taiwan (pp. 3-18). Singapore: Springer.

UNESCO (2008). Mother Tongue Matters: Local Language as a Key to Effective Learning. France: UNESCO.

Wächter, B., \& Friedhelm Maiworm (eds.) (2014). English-Taught Programmes in European Higher Education. The State of Play in 2014. Bonn: Lemmens.

Wang, Ya-Hsuan (2007). Multicultural Literacy Instrumentation: A Reivew and Prospect. Journal of Educational Research and Development, Vol. 3, no. 4., p. 149-179.

Waseda University (2018, March 19) Retrieved from http://www.waseda.jp/admission/en/ 